\title{
Urinary retention presenting as complete bowel obstruction
}

\author{
Dino Papeš, MD; Silvio Altarac, MD, PhD; ${ }^{*}$ Nuhi Arslani, MD, PhD; Zoran Rajković, $M D^{\S}$
}

*Department of Surgery and Urology, Zabok General Hospital, Zabok, Croatia; †Department of Surgery, University Hospital Center Maribor, Maribor, Slovenia; §Department of Surgery and Urology and Department of Trauma Surgery, Zabok General Hospital, Zabok, Croatia

Cite as: Can Urol Assoc J 2013;7(9-10):e637-9. http://dx.doi.org/10.5489/cuaj.347

Published online October 9, 2013.

\section{Abstract}

A 59-year-old male was admitted to hospital for clinical and radiological signs of large bowel obstruction with clinical signs of generalized peritonitis. As such, he was scheduled to undergo emergency exploratory laparotomy. During preoperative preparation, over $2000 \mathrm{~mL}$ of urine was obtained after catheterization. We suggested re-evaluation, and after several hours the symptoms resolved. Although rare, pressure from the distended bladder due to urinary retention can cause complete bowel obstruction and signs of peritonitis. If a large volume of urine is obtained during preoperative preparation for mechanical bowel obstruction, it is recommended to re-evaluate the patient to avoid unnecessary surgery and imaging studies.

\section{Introduction}

Mechanical bowel obstruction is rare and mostly observed in geriatric males. We present a case of bladder distension due to urinary retention.

\section{Case report}

A 59-year-old male was admitted to hospital for strong abdominal pain, vomiting and dehydration. History revealed that the pain started the morning before admission in the lower abdomen; it was colic-like and was worsening. He had nausea, vomiting, and did not pass stool or gas since the pain started. He occasionally noted frequency, straining to void and weak and dribbling urinary stream. The rest of his medical history was unremarkable.

Clinical examination revealed a dehydrated patient in acute distress (tachycardia, restlessness) with pale sweaty skin, decreased skin turgor and dry mouth. His abdomen was grossly distended and diffusely painful (mostly in the lower abdomen) with abdominal guarding. Percussion was painful and revealed tympanic sounds, and on auscultation diminished and tinkling bowel sounds were heard. Digital rectal examination revealed an empty rectum and slightly enlarged non-tender prostate.

Blood tests showed elevated red blood cell count $\left(6.1 \times 10^{6} / \mathrm{mL}\right)$, hematocrit $(59 \%)$ and while blood cell count $(15000$ cells $/ \mathrm{mL})$, low potassium $(2.9 \mathrm{mEq} / \mathrm{L})$ and elevated blood urea nitrogen (BUN) $(20 \mathrm{mg} / \mathrm{dL})$ and creatinine $(1.6 \mathrm{mg} / \mathrm{dL})$, which was consistent with dehydration. Plain abdominal radiograph showed multiple dilated colon loops, with air-fluid levels (Fig. 1); no free air was noted on either chest or abdominal radiographs. Immediate treatment included nil by mouth regimen, nasogastric suction, and intravenous fluid resuscitation. The patient was scheduled to undergo emergency exploratory laparotomy. On urinary catheterization over $2000 \mathrm{~mL}$ of urine was obtained. This suggested that re-evaluation was needed, so laparotomy was deferred. Less than an hour after the catheterization, the patient's condition became better, the pain lessened and there was no abdominal guarding or signs of peritonitis; moreover, the abdominal distension resolved within the next couple of hours. Control abdominal radiography was performed 4 hours after the catheterization, and showed no air-fluid levels (Fig. 2). Complete resolution of symptoms followed in the next 24 hours.

As the patient was able to pass urine on the day of admission, the urinary retention was regarded as chronic. Transrectal ultrasound revealed benign prostatic hyperplasia $(\mathrm{BPH})$, with the prostate size estimated at $60 \mathrm{~mL}$. Renal ultrasound showed no canal dilatation and control BUN and the creatinine and electrolyte levels were normal. Urodynamic testing suggested high pressure chronic urinary retention (rise in detrusor pressure $42 \mathrm{~cm} \mathrm{H}_{2} \mathrm{O}$ ). The patient was given tamsulosin and the urinary catheter was removed after 2 days. Although the trial without catheter (TWOC) was 


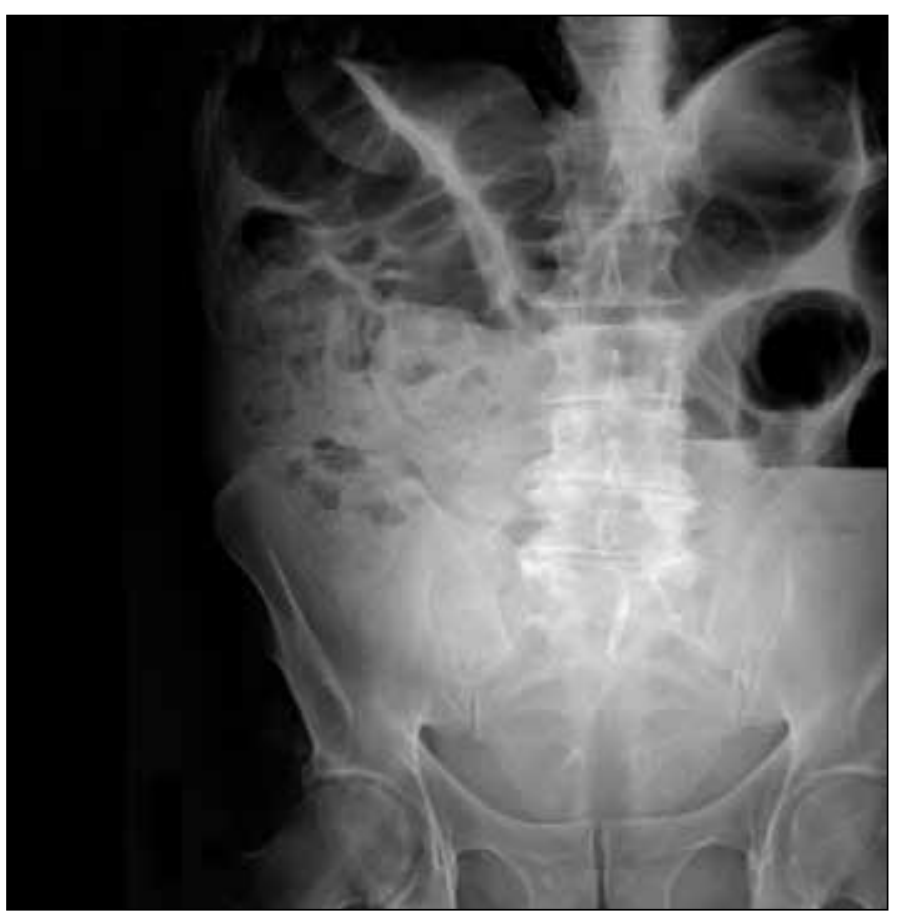

Fig. 1. Plain abdominal radiograph shows multiple dilated colon loops, with airfluid levels - classic signs of bowel obstruction.

successful, he was informed on the nature of his condition and he was scheduled to undergo transurethral resection of prostate in 1 month.

\section{Discussion}

Large bowel obstruction (LBO) is an emergency condition that can result from either mechanical interruption of the flow of intestinal contents or by the dilation of the colon in the absence of an anatomic lesion (pseudo-obstruction or Ogilvie's syndrome).

In western countries about $80 \%$ of LBO is caused by colorectal malignancy, and the rest by a stricture (diverticular, inflammatory, anastomotic, radiation-induced), colonic volvulus, or other rare conditions (hernia, foreign body, benign neoplasm or endometriosis). ${ }^{1}$ Colonic obstruction mostly occurs in elderly patients, due to the higher incidence of main causative factors in this age group. Typically, patients present with inability to pass stool and gas for several days, colicky abdominal pain, abdominal distension, and vomiting. On examination, bowel sounds may be normal early-on, but usually become quiet over time. Because of the large amount of air in the bowel, the abdomen is hyper-resonant to percussion. On palpation the abdomen is usually mildly tender; significant tenderness is indicative of imminent perforation. In cases of perforation, positive peritoneal signs will be noted. Plain abdominal X-ray is the first diagnostic method used and usually shows a distended colon with or without air-fluid levels, and can also differentiate $\mathrm{LBO}$ caused by volvulus.

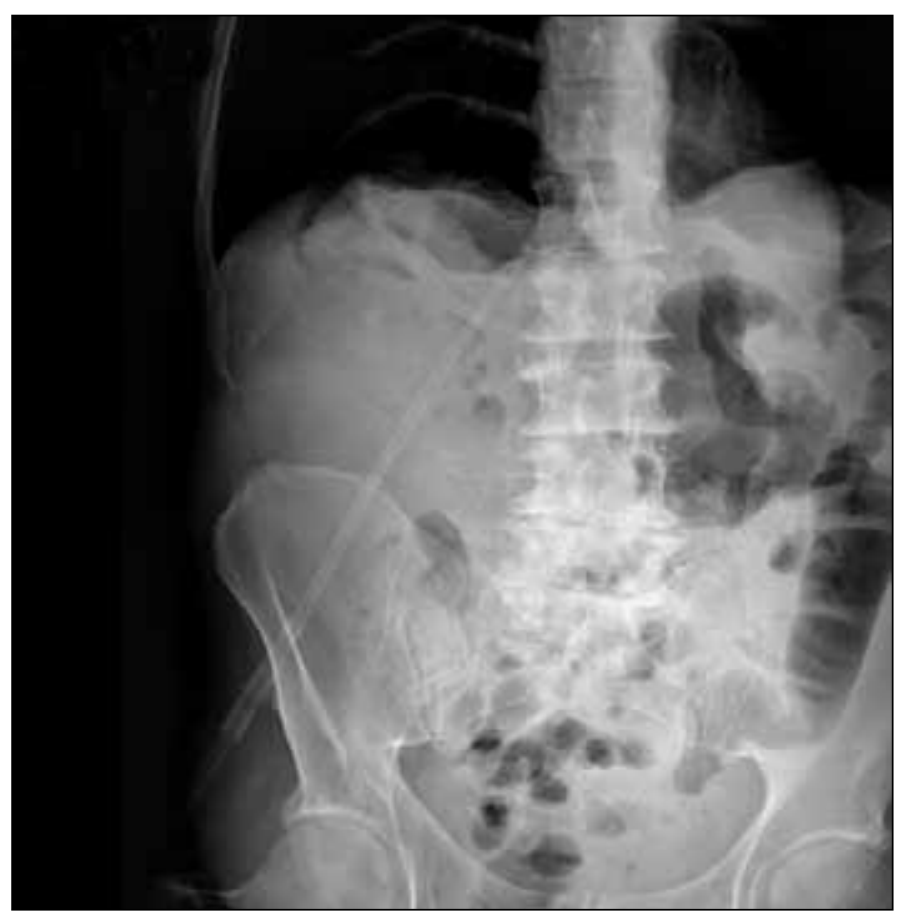

Fig. 2. Two hours after the catheterization, control abdominal radiography showed no air-fluid levels or distension.

The next step is usually a contrast study using water-soluble contrast (e.g., gastrografin). The contrast flows freely to obstruction, where there is a cut-off point. The principle role of this procedure is to confirm the site of obstruction. Also it will exclude patients with intestinal pseudo-obstruction which is of major importance because the treatment differs greatly. ${ }^{2}$ The emergency treatment for LBO includes nil by mouth regimen, nasogastric tube insertion and intravenous fluids resuscitation. Further management depends on the cause of the LBO. In general, LBO caused by malignant obstruction, cecal volvulus or stricture is in most cases treated surgically; in sigmoid volvulus, colonoscopic decompression is the first-line therapy. If these fail, surgery is indicated. Nevertheless, if a patient with clinical and radiographic signs of complete colonic obstruction develops diffuse peritonitis or free intraabdominal air on x-ray, emergency laparotomy is indicated. ${ }^{2}$

We found several reports of constipation caused by urinary retention, ${ }^{3}$ but only 3 reports of patients with complete mechanical bowel obstruction as the initial sign of urinary retention. ${ }^{4-6}$ In all three cases the cause of urinary retention was BPH and a computed tomography (CT) scan was needed to establish the diagnosis. In our case the CT scan was not considered because the patient had abdominal wall guarding, which is an indication for exploratory laparotomy in patients with bowel obstruction.

Our patient had an acute-on-chronic retention since over $1 \mathrm{~L}$ of urine was obtained and he had no previous symptoms. After catheterization, patients with chronic urinary retention may pass a large volume of urine in the first few days, which 
may require electrolyte and fluid resuscitation. ${ }^{7}$ Moreover, hematuria due to renal tract decompression can also occur, but usually resolves within 2 to 3 days. ${ }^{7}$ Those complications did not occur in our patient. Chronic urinary retention may be associated with renal failure, and although our patient did have elevated BUN and creatinine levels, they were due to dehydration since serum potassium was low and the values normalized after fluid resuscitation. After catheterization, patients with chronic urinary retention should undergo urodynamic testing to establish whether they have low- or high-pressure retention which influences further management. ${ }^{8,9}$ Patients with high-pressure retention are more likely to benefit from prostatectomy due to good detrusor function. TWOC can be attempted, although if hydronephrosis or renal impairment is present the patient should remain with indwelling catheter until surgery. ${ }^{7}$ Although our patient had over $1000 \mathrm{~mL}$ of residual urine, which is a factor leading to a high probability of unsuccessful TWOC, ${ }^{10}$ we still decided to pursue TWOC because he was under 65 years old and had good detrusor function. In patients with low-pressure, chronic urinary retention prostatectomy is in many cases unsuccessful as they fail to void completely after surgery and require long-term or clean intermittent self-catheterization. ${ }^{7}$

\section{Conclusion}

If a large volume of urine is obtained during preoperative preparation of a patient with clinical signs of peritonitis and LBO, it is recommended to re-evaluate the patient to avoid unnecessary laparotomy or workup.
Competing interests: None declared.

This paper has been peer-reviewed.

\section{References}

1. Drożdż W, Budzyński P. Change in mechanical bowel obstruction demographic and etiological patterns during the past century: observations from one health care institution. Arch Surg 2012;147:175-80. http://dx.doi.org/10.1001/archsurg.2011.970

2. Nyström PO. Colonic obstruction. In: Schein M, Rogers PN, editors. Schein's Common Sense Emergency Abdominal Surgery. New York: Springer; 2004:217-28.

3. Kleinhaus U, Kaftori J. Rectosigmoid pseudostenosis due to urinary retention. Radiology 1978;127:645-7.

4. Mac Giobuin S, Kavanagh DO, Ryan R, et al. Acute colonic obstruction due to benign prostatic hypertrophy. Ir Med J 2009;102:52-3.

5. Ghebontni L, el-Khoury J, Nguyen-Khac E, et al. Subacute intestinal obstruction due to bladder distension. J Radiol 1998;79:880-2.

6. Maroy B, Moullot P, Daloubeix H. An uncommon cause of transit disorder: compression, by the bladder, of the rectosigmoid junction. Value of barium enema lavage in the profile. Gastroenterol Clin Biol 1989; 13:434-5

7. Kalejaiye 0, Speakman MJ. Management of Acute and Chronic Retention in Men. Eur Urol Suppl 2009;8:523-9. http://dx.doi.org/10.1016/i.eursup.2009.02.002

8. Abrams $P$, Dunn $M$, George N. Urodynamic findings in chronic retention of urine and their relevance to results of surgery. BMJ 1978;2:1258-60. http://dx.doi.org/10.1136/bmi.2.6147.1258

9. Hakenberg OW, Pinnock CB, Marshall VR. Preoperative urodynamic and symptom evaluation of patients undergoing transurethral prostatectomy: analysis of variables relevant for outcome. BJU Int 2003;91:3759. http://dx.doi.org/10.1046/j.1464-410X.2003.04078.x

10. McNeill SA, Hargreave TB; Members of the Alfaur Study Group. Alfuzosin once daily facilitates return to voiding in patients in acute urinary retention. J Urol 2004;171 (6 Pt 1):2316-20. http://dx.doi. org/10.1097/01.ju.0000127743.80759.7a

Correspondence: Dr. Dino Papeš, Department of Surgery and Urology, Zabok General Hospital, Bračak 8, 49210 Zabok, Croatia; dinopapes@gmail.com 